\title{
Patient and relative attitudes to mental hospital closure and transfer into a hospital hostel
}

\author{
Douglas Turkington, Senior Registrar, Department of Psychiatry, Royal Hallamshire \\ Hospital, Glossop Road, Sheffield S10 2JF (correspondence); EMMET LARKIN, \\ Consultant Psychiatrist, Rampton Hospital, Nottinghamshire; and DAvID KINGDON, \\ Consultant Psychiatrist, Bassetlaw General Hospital, Worksop
}

Mental hospital closure and the resultant discharge of patients with chronic psychiatric disabilities into the community has led to public concern (Wallace, 1989). Currently it would seem important to collect as much pertinent data as possible on all aspects of mental hospital closure and the resultant effects on patients and communities. This study focuses on a relatively neglected area in the research literature on community psychiatry and mental health planning, i.e. the opinions of the consumers.

\section{The study}

When a district psychiatric service was established in Bassetlaw, Nottinghamshire it was decided to accept back all long-stay psychiatric patients who had originated from the district and who wished to return. These patients formed a section of the long stay population of Saxondale Hospital (the 'County Asylum'). Following closure all but two of the patients opted to return to Bassetlaw along with two more who for personal reasons wished to move into the area. This gave a group of 17 unselected longstay patients who had been through the closure procedure and had been in community accommodation for a two year period. Diagnostically they were fairly representative of the long-stay population of any large mental hospital. The following diagnostic clusters were constructed from ICD-9 (World Health Organization, 1978): functional psychoses $=11$, neuroses $=3$, personality disorders $=2$, and organic psychosyndrome $=1$. All were initially accepted into two hospital hostels for a period of assessment and rehabilitation. Patients were interviewed individually 24 months after the closure of Saxondale by an independent assessor (EL) from outside the district using the Patient Attitude Questionnaire (PAQ) developed by TAPS. An adapted version, the Relative's Attitude Questionnaire (RAQ) was used to test the opinions of relatives.

\section{Findings}

Of the 17 patients interviewed, all gave apparently reliable responses except for two who had to be excluded from analysis. The first of these patients was mute (conversion hysteria) and the second was dysphasic (neurosyphilis). Just under half of the patients (47\%) wanted to leave Saxondale Hospital at the time of closure, $33 \%$ were unsure and $20 \%$ wished to remain. On the issue of comparison between the two types of care the results were divided into two groups. The larger group of patients $(80 \%)$ were pleased with their new accommodation, preferred it to the hospital and were content to remain there. The smaller group (20\%) were not particularly happy where they were and would prefer to be in their own homes rather than live in the present accommodation indefinitely. Nonetheless, despite their current unhappiness with their lot, none expressed a desire to return to the asylum setting. Contrary to popular belief, this group of long-stay patients were able to give consistent and coherent responses and had quite specific views on the issue of closure and the move into the hospital hostel.

Two of the patients had not been visited since transfer and one patient's relative proved to be uncontactable, leaving 14 out of a possible $17 \mathrm{com}$ pleted interviews. Of the relatives interviewed, $50 \%$ definitely wished their relative to be transferred from the mental hospital into community facilities. The relatives who were unsure about closure $(36 \%)$ were those who had largely lost contact and felt unable to comment. Overall, although not all relatives were necessarily in favour of the patient leaving hospital, of those who had retained contact and had visited the new accommodation, without exception they all preferred it, felt that their relative was satisfied with living there and were happy for their relative to live their permanently. (Tables of results are available from the authors on request.)

\section{Comment}

This study of patient and relative attitudes in relation to mental hospital closure and transfer into a hospital hostel is limited by the low numbers involved. It is, however, representative of a typical district's longstay population and the results hint at an underlying trend of consumer satisfaction. The hospital hostel 
has a high staff to patient ratio and a highly structured environment and no extrapolation of these results should be drawn in relation to discharge into less supervised settings, e.g. group homes, bed and breakfast accommodation etc. Indeed we would tend to agree that for a number of patients continuing care in the hospital hostel is necessary.

Lebow (1983) commented that patient attitudes and satisfaction with service were among the most easily gathered indicators of the quality of a service. Abrahamson et al (1989) showed that these indices could be reliably measured in this particular patient group by interviewing long-stay patients in a mental hospital about their opinions on whether they wished to leave the hospital and their knowledge of accommodation options. As in this study, a majority did not wish to stay permanently in hospital and $68 \%$ of those who said that they did wish to stay changed their mind when offered an alternative. In contrast to the positive views of relatives in our survey, when patients are discharged to live with their relatives a majority express dissatisfaction with various aspects of the service system (Grella \& Grusby, 1989). It may be that it is the next step after the hospital hostel which is potentially the most traumatic both for patients and their relatives if the move is either inappropriate or made too rapidly without an integrated support system under the direction of an energetic case manager.
We hope that this study highlights the value of consultation with patients and their relatives prior to mental hospital closure and increased attention to and investigation of their opinions of their care in a variety of community settings.

\section{Acknowledgements}

We would like to thank Professor Jenner of the Royal Hallamshire Hospital, Sheffield for reviewing the manuscript and the TAPS project for permission to use the Patient Attitude Questionnaire.

\section{References}

Abrahamson, D., Swatton, J. \& Wills, W. (1989) Do long-stay psychiatric patients want to leave hospital? Health Trends, 21, 17-19.

Grella, C. E. \& Grusby, O. (1989) Families of the seriously mentally ill and their satisfaction with services. Hospital and Community Psychiatry, 40, 831-835.

LEBOW, J. L. (1983) Research assessing consumer satisfaction with mental health treatment. Evaluation and Program Planning, 6, 211-236.

WALLACE, M. (1986) A caring community? The plight of Britain's mentally ill. Sunday Times Magazine, 3 May, 25-38.

World Health Organization (1978) Mental Disorders: Glossary and Guide to their Classification in accordance with the ninth revision of the International Classification of Diseases. Geneva: World Health Organization.

\section{The times}

\section{Japanese pharmaceuticals company in London}

A Japanese pharmaceuticals company, Eisai, is to spend $£ 50$ million on setting up a research centre in Britain. The money will be spread over 15 years. The company has chosen University College, London (UCL) as the location for a centre for the neurosciences with the aim of undertaking basic research into diseases of the central nervous system such as multiple sclerosis, Parkinson's disease and Alzheimer's disease.
The company hopes to attract about 35 scientists from the US, Japan and Europe. These staff will also hold part-time teaching and research posts at the university. Eisai will retain intellectual property rights to any potential product that arises from research at the centre. The company is also establishing the terms by which it will share the rights to the fruits of collaborative research between its own staff and scientists working for the university. 